\title{
Therapeutic deep lamellar keratoplasty for corneal perforations
}

\author{
Abstract \\ Objectives/aims Corneal perforation \\ can be potentially blinding unless the \\ integrity of the globe is restored quickly. \\ Although penetrating keratoplasty (PK) \\ may achieve this, it carries a high risk of \\ endothelial rejection in inflamed eyes. Deep \\ lamellar keratoplasty (DLK) may be an \\ alternative option to $\mathrm{PK}$ in such eyes owing to \\ its potential for a lower incidence of rejection. \\ We report the efficacy of DLK in patients with \\ corneal perforations.
}

Patients and methods Four patients underwent layer-by-layer DLK for noninfective corneal perforation, after measures such as the use of a bandage contact

Tennent Institute of Ophthalmology, Gartnavel General Hospital, Glasgow, UK

Correspondence: PR Bhatt, Tennent Institute of Ophthalmology, Gartnavel General Hospital, Great Western Road, Glasgow G12 OYN UK Tel: + 441412111039 ; Fax: + 441412112054 E-mail: priyarbhatt@ hotmail.com

Received: 16 February 2006 Accepted in revised form: 7 April 2006 Published online: 12 May 2006

Part of this work was presented as an oral presentation at the 10th Nottingham Eye Symposium, 2006 and as a poster at the Annual Congress of the Royal College of

Ophthalmologists, Manchester 2006 lens, tissue adhesive, and conjunctival pedicle flap had failed. The preoperative visual acuity was hand movements in one patient, 1/60 in two, and 6/60 in one. All four had iris incarcerated within the corneal perforations. SF6 gas (three patients) and air (one patient) were injected into the anterior chamber at the end of surgery.

Results The integrity of the globe was restored in all four patients with an improvement in visual acuity $(6 / 60$ in one and $6 / 36$ or better in three). The mean follow-up time was 7 months. All four patients had clear corneas 3 months postoperatively, apart from the area of the original perforation. There was no recurrence of ulceration or perforation.

Conclusion DLK is a safe and effective therapeutic measure in the management of patients with corneal perforations acting to preserve the integrity of the globe and restore vision.

Eye (2007) 21, 1168-1173; doi:10.1038/sj.eye.6702428; published online 12 May 2006

Keywords: corneal perforation; deep lamellar keratoplasty; penetrating keratoplasty
PR Bhatt, LT Lim and K Ramaesh

Introduction

Corneal perforation is an ocular emergency and, if not managed promptly and effectively, can have devastating consequences. Of prime importance is the restoration of the integrity of the globe and ocular tension. Short-term measures have included therapeutic soft contact lenses, tissue adhesives, epithelial transplantation, scleral patch grafts, conjunctival flaps, and amniotic membrane transplantation. $^{1-7}$

Although these procedures may restore the integrity of the globe, they fail to achieve a clear visual axis. Penetrating keratoplasty (PK) eliminates the scar and corneal surface abnormalities, offering a chance of visual recovery, but its success in the presence of inflammation has been variable and generally poor. ${ }^{1,8,9}$ Penetrating keratoplasties performed in the acute setting of corneal perforation are more likely to fail. ${ }^{9}$ Deep lamellar keratoplasty (DLK) involves dissection of the host's corneal stroma down to the level of Descemet's membrane. ${ }^{10,11}$ It offers a significant advantage over PK in terms of endothelial graft rejection and prevention of long-term endothelial loss. ${ }^{10-14}$ The successful use of DLK in corneal perforation has only been reported in two cases in the literature. ${ }^{15}$ We present four cases of noninfectious corneal perforation managed by DLK.

Patients and methods

Four patients with noninfectious corneal perforation underwent DLK. Patient age ranged from 11 to 70 years (mean average age 46.8 years). All patients had pre-existing comorbidity. Patient 1 had a long history of herpetic disciform keratitis and developed a descemetocele and subsequent perforation. A bandage contact lens (BCL) followed by a conjunctival pedicle graft (CPG) had failed to 
stabilise the eye. Patient 2 suffered with rheumatoid arthritis and dry eyes and presented with inferior corneal thinning and perforation, which had been managed unsuccessfully with a BCL and tissue adhesive. Patient 3 had dry eye secondary to lacrimal gland damage following orbital surgery for a dermoid cyst. He developed a corneal ulcer which perforated and had been managed in the short term with a BCL and subsequently tissue adhesive. Patient 4 was a young girl, referred with corneal perforation who had had a red eye for 2 months and had ocular surface inflammation of undetermined cause. She had been managed with a BCL as an emergency measure. The details and outcome for each patient are shown in Table 1.

\section{Surgical technique}

\section{Recipient}

All surgery was performed by the same surgeon (KR) under general anaesthesia. $10 \%$ povidone iodine was applied to the eye preoperatively for 30 seconds and then washed with sterile balanced salt solution (BSS). In all four patients, iris was incarcerated in the wound and this was reposited at the beginning of the procedure with viscoelastic (Healonid, AMO). The anterior chamber was reformed with viscoelastic to prevent abrasion of the endothelium against the iris. A coronet corneal trephine (Vision Matrix, Harrogate) was used to mark the recipient cornea. The groove was manually dissected up to approximately 50\% corneal depth. A 27-gauge needle connected to a syringe filled with air was inserted into the corneal stroma and air was injected, rendering the corneal tissue opaque. This was followed by injection of BSS into the corneal stroma to achieve separation of collagen fibres. The BSS causes the stromal tissue to swell and facilitates partial thickness anterior keratectomy to about $80 \%$ thickness of the corneal stroma. The deeper layer of the corneal stroma was dissected layer by layer using a Beaver blade up to $95 \%$ thickness. We did not attempt to bare the Descemet's membrane completely. The stroma surrounding the area of perforation was dissected last and some strands left in situ.

\section{Donor}

Human eye bank eyes stored in organ culture medium (Optisol solution, Medium Eagles mem, 2\% FBS) were used. Donor corneoscleral rims were placed on a sterile rubber block (the under surface of the donor punch). Using a dry cellulose sponge, the posterior corneal surface was swabbed to remove the endothelium and Descemet's membrane. A 0.25 or $0.50 \mathrm{~mm}$ oversized donor corneal button was then punched out with a coronet corneal trephine (Vision Matrix, Harrogate). The donor button was transferred to the recipient bed and sutured in place with interrupted 10.0 monofilament nylon sutures.

SF6 gas (three patients) and air (one patient) were injected into the anterior chamber at the end of surgery. Air was used in the first patient, but was replaced by SF6 in the subsequent three patients, as we felt this would provide more effective and long-lasting tamponade. A subconjunctival injection of betamethasone and cefuroxime was given at the end of the procedure. Patients were commenced on prednisolone $0.1 \%$ drops four times daily and cefuroxime 5\% drops four times daily postoperatively. Patient 1 received oral aciclovir $400 \mathrm{mg}$ twice daily postoperatively. Patients 2 and 3 received oral prednisolone postoperatively $(40 \mathrm{mg}$ for 5 days), as these patients were felt to have increased ocular inflammation and therefore an increased risk of rejection.

Table 1 Characteristics and outcome of the 4 patients undergoing DLK

\begin{tabular}{|c|c|c|c|c|c|c|c|}
\hline Case & Age & Sex & Comorbidity & $\begin{array}{l}\text { Size and location of } \\
\text { perforation }\end{array}$ & $\begin{array}{l}\text { Previous } \\
\text { management }\end{array}$ & $\begin{array}{l}\text { Preop } \\
\text { BCVA }\end{array}$ & $\begin{array}{l}\text { Postop BCVA } \\
\text { (3 months) }\end{array}$ \\
\hline 1 & 70 & $\mathrm{~F}$ & $\begin{array}{l}\text { Chronic HSV keratitis } \\
\text { Anaesthetic cornea } \\
\text { Cataract }\end{array}$ & $1.5 \mathrm{~mm}$, paracentral & $\mathrm{BCL}, \mathrm{CPG}$ & $1 / 60$ & $6 / 36$ \\
\hline 2 & 55 & $\mathrm{~F}$ & $\begin{array}{l}\text { Rheumatoid arthritis } \\
\text { Dry eye } \\
\text { Corneal melt }\end{array}$ & $\begin{array}{l}3 \mathrm{~mm}, \\
\text { mid-periphery }\end{array}$ & BCL, TA & $6 / 60+1$ & $6 / 9$ \\
\hline 3 & 51 & M & $\begin{array}{l}\text { Lacrimal gland damage following } \\
\text { orbital surgery for dermoid cyst } \\
\text { Moderate dry eye and } \\
\text { steroid-induced glaucoma } \\
\text { Anaesthetic central cornea }\end{array}$ & $1.5 \mathrm{~mm}$, paracentral & $\mathrm{BCL}, \mathrm{TA}$ & $\mathrm{HM}$ & $6 / 60$ \\
\hline 4 & 11 & $\mathrm{~F}$ & $\begin{array}{l}\text { Chronically inflamed eye of } \\
\text { unknown aetiology }\end{array}$ & $2 \mathrm{~mm}$, mid-periphery & $\mathrm{BCL}$ & $1 / 60$ & $6 / 36$ \\
\hline
\end{tabular}

BCVA, best-corrected visual acuity; HSV, herpes simplex keratitis; BCL, bandage contact lens; CPG, conjunctival pedicle graft; TA, tissue adhesive; HM, hand movements. 
The patients were advised to maintain a face-up position for 3 days after surgery.

\section{Results}

Preoperative visual acuity ranged from hand movements to $1 / 60$. In all four patients there were no additional intraoperative complications. The integrity of the globe was restored in all four patients. One patient (case 2) had a double anterior chamber, which resolved on its own.

Mean average follow-up time was 7 months (range 3-18 months). At 3 months postoperatively, all four patients had clear corneas, apart from the area of the original perforation (Figure 1). All four patients showed an improvement in visual acuity $(6 / 60$ in one and 6/36 or better in three). There was no recurrence of ulceration or perforation.
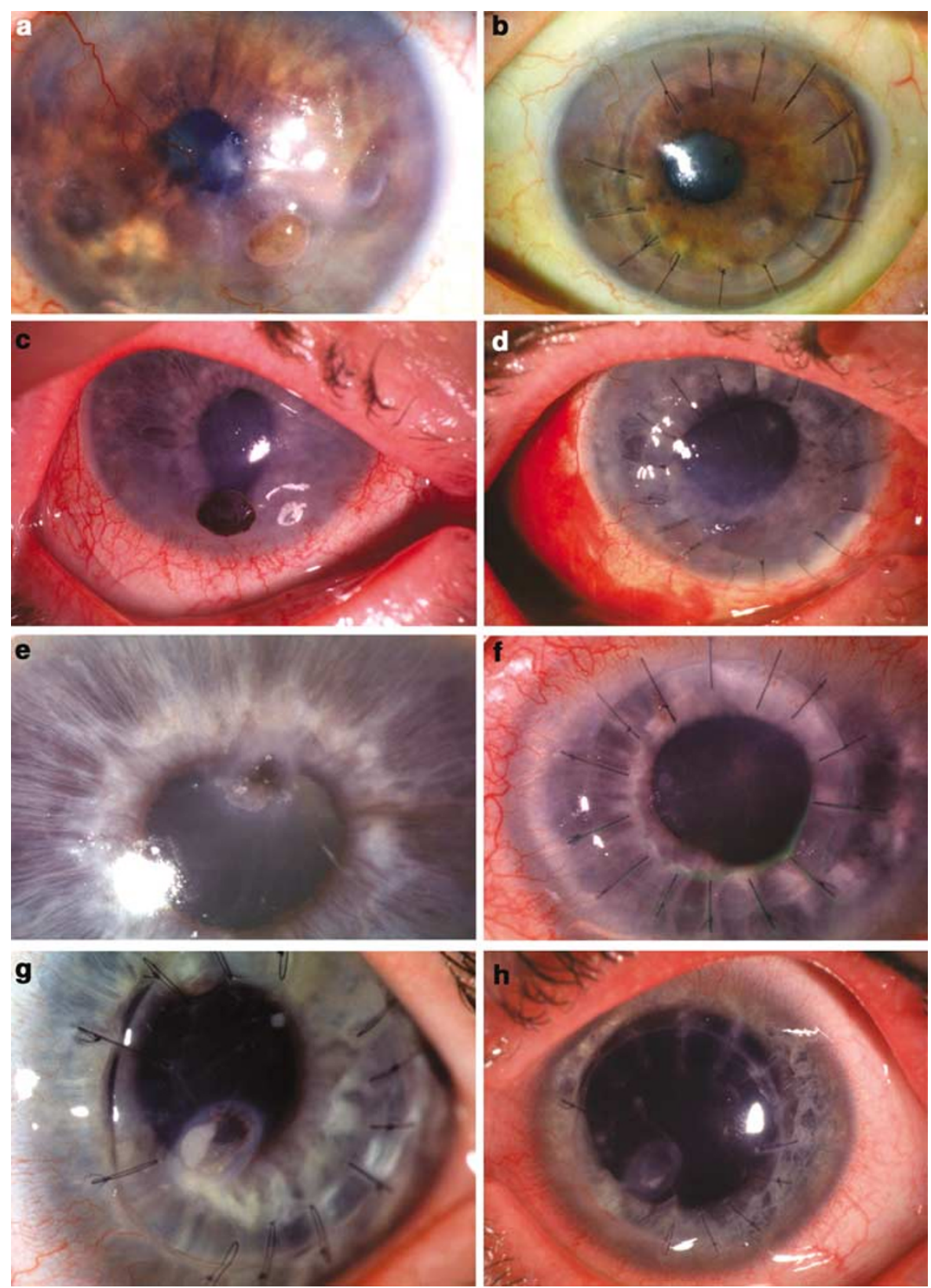

Figure 1 Photographs of Case 1 (a) pre-DLK, (b) 3 months after DLK showing off-centre scarring from original corneal perforation; Case 2 (c) pre-DLK, (d) 3 months after DLK showing some residual corneal interface haze; Case 3 (e) pre-DLK, (f) 3 months after DLK showing minimal scarring at the site of original perforation; Case $4(\mathrm{~g})$ no pre-DLK photo was taken. This is the appearance at 1-month post-DLK and (h) 3 months after DLK showing an increase in corneal clarity. 
Patient 1 presented with reduced visual acuity and generalised epithelial and stromal haze 17 months postoperatively. She was treated as an early stromal rejection and given oral aciclovir and intensive topical corticosteroids. Her visual acuity improved and the cornea cleared over the subsequent month. Her graft is currently healthy and she is awaiting cataract surgery.

\section{Discussion}

There are numerous medical and surgical treatment options for managing corneal perforation. Unless the integrity of the globe is restored quickly, persistent leak and hypotony lead to high ocular morbidity and eventual enucleation or evisceration. ${ }^{1,2}$ Emergency measures such as BCLs and the use of tissue adhesive have been shown to reduce the enucleation outcome. ${ }^{2}$ Tissue adhesives may be synthetic (cyanoacrylate derivatives) or biologic (fibrin glue). Both types have been shown to be effective in the closure of small corneal perforations (up to $3 \mathrm{~mm}$ in diameter) but fibrin glue is associated with reduced foreign body reaction and less corneal vascularisation. ${ }^{6}$ If these methods fail, surgical intervention in the form of a scleral patch graft, CPG, or amniotic membrane transplantation may be performed. ${ }^{1,5,7,16-18}$
Conjunctival flaps restore ocular surface integrity, provide mechanical support, and are thought to promote healing by neutralising collagenases implicated in corneal melting. ${ }^{5,7}$ Gundersen ${ }^{19}$ described a technique that involved a $360^{\circ}$ peritomy, with coverage of the entire cornea with conjunctiva. Recently described techniques use a partial, pedunculated conjunctival flap or graft, which does not limit visualisation of the anterior segment and allows corneal disease progression to be monitored. 5,7 However, this technique may still lead to significant vascularisation of the cornea, compromising visual potential and reducing the probability of success of subsequent keratoplasty.

Amniotic membrane transplantation has been employed in patients with corneal ulcers and perforation, acting both as a graft to replace damaged ocular surface stroma and as a patch to reduce inflammation and promote healing. ${ }^{16-18,20}$ Its epithelium expresses growth factors that facilitate epithelial healing and it also contains inhibitory proteases that may downregulate the inflammatory cells that contribute to corneal melting. ${ }^{18,20}$ However, corneal stromal thickness may only be partially restored ${ }^{20}$ and the persisting corneal thinning with associated irregular astigmatism may affect final visual acuity.

Table 2 Relative advantages and disadvantages of PK, DLK, and LK in the management of corneal perforations

\begin{tabular}{|c|c|c|}
\hline Type of graft & Advantages & Disadvantages \\
\hline PK & $\begin{array}{l}\text { - No stromal interface. Therefore, potential to } \\
\text { achieve relatively clear cornea } \\
\text { - Suitable for central perforations }\end{array}$ & $\begin{array}{l}\text { - Requires donor cornea that is healthy and age } \\
\text { matched } \\
\text { - PK in the setting of a perforation carries a high risk of } \\
\text { endothelial rejection } \\
\text { - Will require intensive topical steroids } \pm \text { systemic } \\
\text { immune suppression to prevent rejection } \\
\text { - Side effects of topical and systemic immunosuppression } \\
\text { can be serious } \\
\text { - Peripheral perforations will require larger grafts, which } \\
\text { carry a high risk of rejection }\end{array}$ \\
\hline LK & $\begin{array}{l}\text { - Does not require healthy endothelium } \\
\text { - } \quad \downarrow \text { risk of rejection, only the stroma is liable } \\
\text { to immune response } \\
\text { - Suitable for peripheral and paracentral } \\
\text { perforations }\end{array}$ & $\begin{array}{l}\text { - Stromal interface haze can seriously interfere } \\
\text { with vision } \\
\text { - Lamellar dissection of donor material may require a } \\
\text { whole globe } \\
\text { - Not suitable for central large perforations }\end{array}$ \\
\hline DLK & $\begin{array}{l}\text { - Does not require healthy endothelium } \\
\text { - Only the stroma is transplanted } \\
\downarrow \text { risk of rejection, only the stroma is } \\
\text { liable to immune response } \\
\text { - Preparation of the donor material is } \\
\text { relatively easy } \\
\text { - Organ culture media-stored cornea } \\
\text { can be used } \\
\text { - Suitable for peripheral and } \\
\text { paracentral perforations }\end{array}$ & $\begin{array}{l}\text { - Dissection of the corneal stroma in a hypotonous eye } \\
\text { is technically difficult but achievable } \\
\text { - Requires injection of SF6 or air into the } \\
\text { anterior chamber. May develop double anterior } \\
\text { chamber } \\
\text { - Not suitable for central large perforations }\end{array}$ \\
\hline
\end{tabular}


Therapeutic keratoplasty offers benefits over the above interventions in terms of visual potential but obviously requires donor tissue. Lamellar keratoplasty (LK) has been employed as a temporising measure in corneal perforations. ${ }^{1,21-23}$ LK involves transplantation of donor epithelium and stroma and is therefore not associated with endothelial immunologic rejection. However, the observed stromal interface opacification limits optical success. ${ }^{21-24}$ Lamellar dissection of donor material also requires a whole globe if an artificial anterior chamber is not available. DLK involves a deeper dissection to the level of Descemet's membrane ${ }^{11}$ and has a reduced incidence of interface haze compared to LK. ${ }^{11,24}$ Preparation of the donor material is relatively easy and organ culture media-stored cornea can be used.

DLK has shown comparable visual results to PK..$^{13,14,25}$ Studies to date have involved patients with keratoconus and those without endothelial abnormalities. Although DLK is considered to be technically more challenging, it offers significant advantages over PK. Visual rehabilitation may occur faster in DLK as keratometric astigmatism has been found to be lower than in PK and healing may occur quicker as sutures can be removed at a much earlier date. ${ }^{25}$ Postoperative corticosteroid drops may be discontinued earlier in DLK. This may explain why intraocular pressure is more commonly raised after PK than DLK. ${ }^{13}$ More importantly, as a result of preservation of recipient endothelium in DLK, graft rejection rates are low and unlike PK it has a minimal effect on endothelial cell loss. ${ }^{11-14,26}$ In the few reports of stromal graft rejection in DLK, as in patient 1 in this study, reversal of stromal oedema and full recovery of visual function has occurred with intensive topical corticosteroids. ${ }^{27}$ This is of particular relevance when considering corneal grafting in inflamed eyes when the risk of rejection is higher. (The relative advantages and disadvantages of PK, LK, and DLK are summarised in Table 2.)

DLK appears to be an effective treatment option for corneal perforation. In all four of our patients, DLK was successful in restoring the integrity of the globe and improving visual function. The corneas remained clear except for the area of the original perforation where a scar formed. (There was no bullous keratopathy at the site of perforation.) Scar formation did not appear to adversely affect final visual outcome.

\section{References}

1 Portnoy SL, Insler MS, Kaufman HE. Surgical management of corneal ulceration and perforation. Surv Ophthalmol 1989; 34(1): 47-58.
2 Hirst LW, Smiddy WE, Stark WJ. Corneal perforations. Changing methods of treatment, 1960-1980. Ophthalmology 1982; 89(6): 630-635.

3 Kobayashi A, Shirao Y, Segawa Y, Kawasaki K, Tanahashi T, Komata $\mathrm{M}$ et al. Temporary use of a customized, glued-on hard contact lens before penetrating keratoplasty for descemetocele or corneal perforation. Ophthalmic Surg Lasers Imaging 2003; 34(3): 226-229.

4 Leibowitz HM. Hydrophilic contact lenses in corneal disease. IV. Penetrating corneal wounds. Arch Ophthalmol 1972; 88(6): 602-606.

5 Sandinha T, Zaher SS, Roberts F, Devlin HC, Dhillon B, Ramaesh K. Superior forniceal conjunctival advancement pedicles (SFCAP) in the management of acute and impending corneal perforations. Eye 2006; 20(1): 84-89.

6 Sharma A, Kaur R, Kumar S, Gupta P, Pandav S, Patnaik B et al. Fibrin glue versus $N$-butyl-2-cyanoacrylate in corneal perforations. Ophthalmology 2003; 110(2): 291-298.

7 Khodadoust A, Quinter AP. Microsurgical approach to the conjunctival flap. Arch Ophthalmol 2003; 121(8) 1189-1193.

8 Arentsen JJ, Laibson PR, Cohen EJ. Management of corneal descemetoceles and perforations. Ophthalmic Surg 1985; 16(1): 29-33.

9 Tragakis MP, Rosen J, Brown SI. Transplantation of the perforated cornea. Am J Ophthalmol 1974; 78(3): 518-522.

10 Anwar M, Teichmann KD. Deep lamellar keratoplasty: surgical techniques for anterior lamellar keratoplasty with and without baring of Descemet's membrane. Cornea 2002; 21(4): 374-383.

11 Sugita J, Kondo J. Deep lamellar keratoplasty with complete removal of pathological stroma for vision improvement. Br J Ophthalmol 1997; 81(3): 184-188.

12 Panda A, Bageshwar LM, Ray M, Singh JP, Kumar A. Deep lamellar keratoplasty versus penetrating keratoplasty for corneal lesions. Cornea 1999; 18(2): 172-175.

13 Shimazaki J, Shimmura S, Ishioka M, Tsubota K. Randomized clinical trial of deep lamellar keratoplasty vs penetrating keratoplasty. Am J Ophthalmol 2002; 134(2): 159-165.

14 Watson SL, Ramsay A, Dart JK, Bunce C, Craig E. Comparison of deep lamellar keratoplasty and penetrating keratoplasty in patients with keratoconus. Ophthalmology 2004; 111(9): 1676-1682.

15 Shimmura S, Shimazaki J, Tsubota K. Therapeutic deep lamellar keratoplasty for cornea perforation. Am J Ophthalmol 2003; 135(6): 896-897.

16 Hanada K, Shimazaki J, Shimmura S, Tsubota K. Multilayered amniotic membrane transplantation for severe ulceration of the cornea and sclera. Am J Ophthalmol 2001; 131(3): 324-331.

17 Ma DH, Wang SF, Su WY, Tsai RJ. Amniotic membrane graft for the management of scleral melting and corneal perforation in recalcitrant infectious scleral and corneoscleral ulcers. Cornea 2002; 21(3): 275-283.

18 Prabhasawat P, Tesavibul N, Komolsuradej W. Single and multilayer amniotic membrane transplantation for persistent corneal epithelial defect with and without stromal thinning and perforation. Br J Ophthalmol 2001; 85(12): 1455-1463. 
19 Gundersen T. Conjunctival flaps in the treatment of corneal disease with reference to a new technique of application. AMA Arch Ophthalmol 1958; 60(5): 880-888.

20 Rodriguez-Ares MT, Tourino R, Lopez-Valladares MJ, Gude F. Multilayer amniotic membrane transplantation in the treatment of corneal perforations. Cornea 2004; 23(6): 577-583.

21 Shimmura S. Component surgery of the cornea. Cornea 2004; 23(8, Suppl): S31-S35.

22 Dohlman CH, Boruchoff SA, Sullivan GL. A technique for the repair of perforated corneal ulcers. Arch Ophthalmol 1967; 77(4): 519-525.

23 Titiyal JS, Ray M, Sharma N, Sinha R, Vajpayee RB. Intralamellar autopatch with lamellar keratoplasty for paracentral corneal perforations. Cornea 2002; 21(6): 615-618.

24 Richard JM, Paton D, Gasset AR. A comparison of penetrating keratoplasty and lamellar keratoplasty in the surgical management of keratoconus. Am J Ophthalmol 1978; 86(6): 807-811.

25 Trimarchi F, Poppi E, Klersy C, Piacentini C. Deep lamellar keratoplasty. Ophthalmologica 2001; 215(6): 389-393.

26 Bhojwani RD, Noble B, Chakrabarty AK, Stewart OG. Sequestered viscoelastic after deep lamellar keratoplasty using viscodissection. Cornea 2003; 22(4): 371-373.

27 Al-Torbak A, Malak M, Teichmann KD, Wagoner MD. Presumed stromal graft rejection after deep anterior lamellar keratoplasty. Cornea 2005; 24(2): 241-243. 